Sustainability Reporting.

A comparative analysis in Portuguese and Brazilian major companies

\begin{abstract}
Environmental, social and economic disasters became sustainability a central topic in global agenda during the twentieth century. It generates more society's awareness regarding environmental problems and companies concerns on the topic, causing the inclusion of sustainability issues as one of the priorities in their strategic plans. Organizations' components of sustainability have been created with different focus and priorities, it originated significant differences in how organizations approach sustainability in terms of objectives, policies and initiatives chosen (EIRIS, 2012). Sustainable reports publications have been the main communication vehicle of organization approaches. This study aims, through an exploratory approach, to understand sustainability metrics adopted in organizational environment and to analyze how the top ten Brazilian and Portuguese companies - listed on the BOVESPA and EURONEXT Lisbon - internalize sustainability practices and utilize their sustainability reports as a marketing tool.
\end{abstract}

Keywords: Sustainability, Report, Communication, Global Reporting Initiative, Marketing

\title{
Pedro Anunciação
}

Escola Superior de Ciências Empresarias do Instituto Politécnico de Setúbal

\section{Duarte Xara-Brasil}

Escola Superior de Ciências Empresarias do Instituto Politécnico de Setúbal

\section{Jane Marques}

Escola de Artes, Ciências e Humanidades da Universidade de São Paulo

Agatha Matias

Escola de Artes, Ciências e Humanidades da Universidade de São Paulo

\section{Camila Garcia}

Escola de Artes, Ciências e Humanidades da Universidade de São Paulo

Anunciação, P., Xara-Brasil, D., Marques, J., Matias, A., \& Garcia, C. (2016). Sustainability Reporting: A Comparative Analysis in Portuguese and Brazilian Major Companies. International Journal of Sustainable Economies Management (IJSEM), 5(4), 10-24. EISSN: 2160-9667 DOI. 10.4018/IJSEM.2016100102 